\title{
A Survey of AI in Operations Management from 2005 to 2009
}

\author{
Khairy A. H. Kobbacy*, Sunil Vadera+ \\ *School of Built Environment, \\ +School of Computing, Science and Engineering \\ University of Salford, Salford M5 4WT, UK \\ Appears in Journal of Manufacturing Technology Management, 2011, Vol 2, Issue 6, pp706-733
}

\begin{abstract}
Purpose: The use of AI for operations management, with its ability to evolve solutions, handle uncertainty and perform optimisation continues to be a major field of research. The growing body of publications over the last two decades means that it can be difficult to keep track of what has been done previously, what has worked, and what really needs to be addressed. Hence this paper presents a survey of the use of AI in operations management aimed at presenting the key research themes, trends and directions of research.
\end{abstract}

Design/methodology/approach: The paper builds upon our previous survey of this field which was carried out for the 10 year period 1995 to 2004 (Kobbacy et al. 2007). Like the previous survey, it uses the Elsevier's ScienceDirect database as a source. The framework and methodology adopted for the survey is kept as similar as possible to enable continuity and comparison of trends. Thus the application categories adopted are: (a) design, (b) scheduling, (c) process planning and control and (d) quality, maintenance and fault diagnosis. Research on utilising neural networks, case based reasoning, fuzzy logic, knowledge based systems, data mining, and hybrid AI in the four application areas are identified.

Findings: The survey categorises over 1400 papers, identifying the uses of AI in the four categories of operations management and concludes with an analysis of the trends, gaps and directions for future research. The findings include: (a) The trends for Design and Scheduling show a dramatic increase in the use of GAs since 2003-04 that reflect recognition of their success in these areas, (b) A significant decline in research on use of KBS, reflecting their transition into practice, (c) an increasing trend in the use of fuzzy logic in Quality, Maintenance and Fault Diagnosis, (d) surprising gaps in the use of CBR and hybrid methods in operations management that offer opportunities for future research.

Originality/value: This is the largest and most comprehensive study to classify research on the use of AI in operations management to date. The survey and trends identified provide a useful reference point and directions for future research.

Keywords: Operations Management, Artificial Intelligence

\section{INTRODUCTION AND METHODOLOGY}

The field of operations management continues to provide a fertile ground for researchers, with ever increasing pressures for organisations to become more competitive, to meet global challenges, to become more eco-friendly and to comply with increasing legislation. The use of AI, with its ability to evolve solutions, handle uncertainty and perform optimisation seems to be the primary means of tackling these challenges. The number of publications and studies utilising AI for operations management appears to be growing rapidly. For example, in our 
survey in 2004 (Kobbacy et al. 2007) we identified over 1200 papers in the field. The danger with so many publications is of course, that researchers find it difficult to keep track of what has been done, what has worked, what has proved not to work well and what really needs to be addressed. Ultimately, there is a danger that although the publications increase, much of it may be similar and we don't actually build upon previous results to make substantial progress. Hence, whenever we've organised the European Conference on Intelligent Management Systems in Operations, the fourth of which was held in July 2009, we've carried out a survey in the hope that it will help to raise awareness of the current status of the field, what has been published, and identify trends and scientific gaps.

The methodology and framework we use is similar to that adopted in our previous survey. In carrying out the survey, we have used the following areas of Operations Management, with one of the authors (KAHK) assuming responsibility for Process Planning and Control and Quality, Maintenance and Fault Diagnosis and the other author (SV) assuming responsibility for the areas of Design and Scheduling. Likewise, we have retained the areas in our previous survey but added the data mining to represent methods such as association rule mining and decision tree learning which is a growing area of interest:

- Case Based Reasoning (CBR).

- Genetic Algorithms (GAs).

- Neural Networks (NN)

- Knowledge Based Systems (KBS)

- Fuzzy logic (FL)

- Data Mining (DM).

The Science Direct Database was used to search for references using fairly obvious keywords. So for example, the terms "CBR", "Case based reasoning" and "scheduling" are used to identify papers on CBR and scheduling. Further filtering and some judgement are, of course, needed to remove irrelevant papers, and to avoid double counting of papers. However, in most cases, it was possible to make a classification based upon the title and abstract of a paper.

The paper is organised as follows. Section 2 of the paper gives a flavour of the publications in each category and Section 3 provides the quantitative data and concludes the paper.

\section{SURVEY AND REPRESENTATIVE RESEARCH}

\subsection{DESIGN}

The rate of publications on using AI to aid design has grown from around 50 papers per year in our previous survey to over 80 papers per year, with the most significant growth being in the use of GAs and an increase in using fuzzy logic.

\subsubsection{Fuzzy Logic and Design}

Fuzzy logic continues to be employed in the design of controllers. So for example, Andújar \& Barragán (2005) utilise fuzzy logic as a basis for a procedure to design a multi-variate nonlinear controller that is general enough to handle the use of any fuzzy membership function 
used to model a plant. Ababneh et al. (2009) show how the use of a Takagi-Sugeno fuzzy model can aid the challenging task of designing a digital controller for a chaotic system.

There are several uses of fuzzy logic in eco-design. Vakili et al. (2007) point out the difficulties of designing eco-friendly products since factors such as social and environmental impact can be vague. Hence, they take advantage of fuzzy logic's ability to model imprecise factors and deduce an indication of the extent to which a design is eco-efficient. Kuo et al. (2009) argue that although several companies have designed eco-friendly products, these have not been as successful as anticipated, perhaps because their designs ignore cost and customer requirements. Hence they propose the use of fuzzy logic to model customer requirements as well as eco-friendly requirements in an attempt to produce better balanced designs.

\subsubsection{KBS in Design}

There appears to be minimal research on use of KBS for design. Perhaps this is no longer fashionable or it may be that researchers have given up on attempts to elicit and represent knowledge from human experts. There are some optimists though, who continue to believe in their value. Farinha et al. (2005), for example, suggest that we are "far from taking full advantage of knowledge based systems" and proceed to describe three prototype applications in civil engineering. The only other study that uses KBS is by Hernández \& Arjona (2007) who combine finite element models and heuristics to develop an aid for designing transformers.

\subsubsection{CBR in Design}

Design, by its very nature, is a skill based activity and requires experience. Hence there are many applications of CBR in design, including the following typical examples.

Avramenko \& Kraslawski $(2005 ; 2006)$ show how CBR can be used to design reactive distillation systems and develop a scheme for representation of cases that facilitate assessment of similarity and retrieval.

Cortes Robles et al. $(2008 ; 2009)$ argue that the need for design aids in chemical engineering is greater than ever given the increasing demands from fields such as nanotechnologies and the reducing reserves of hydrocarbon. They develop a tool based on the theory of inventive problem solving and case based reasoning that aids design. Lai \& Chang (2006) emphasise the importance of interaction and discussion in the design process and show how CBR can be incorporated as part of a dynamic role play based system.

One of the most interesting studies in this period is the work by Davies et al. (2009) on how humans design by analogy. They study the behaviour of four human designers when using analogy and then develop a computational model and system called Galatea for creating designs.

\subsubsection{GAs in Design}


GAs have been used in many domains of application including design of structures, in drug design and in the design of hypersonic vehicles.

Kaveh \& Rahami (2006) utilise GAs in the design of structures to meet stress constraints, including material non-linearity and to optimise the dimensions of the structure.

Narayana Naik et al. (2008) utilise GAs in the design of minimum weight laminates subject to failure criteria such as fibre breaks, cracks, crushing. A study by Degertekin et al. (2008) compares the use of GAs and Tabu search for the design of non-linear geometric steel frames. The aim is to design minimum weight steel frames utilising a standard set of steel sections subject to constraints on loads, resistance, interstorey drift and other similar constraints. Interestingly, the study concludes that Tabu search produced lighter structures than use of GAs.

Che \& Tang (2008) use multi-objective GAs in the design of a hypersonic vehicle. They use GAs to optimise several parameters including stability, ability to manoeuvre and aerodynamics. The results obtained were evaluated using a wind tunnel and confirmed the benefits of using GAs.

Several studies utilise GAs for designing buildings. Wang, Rivard \& Zmeurenu (2006) study the use of GAs for design of floor shape which has an impact on energy utilisation and construction costs of buildings. They consider two alternative gene representations for this problem and evaluate them with the aid of a case study. Lee (2007) shows how computational fluid dynamics together with GAs can be used to design buildings to facilitate optimal indoor climates taking account of variable outdoor conditions, and the operation of HVAC systems. Ooka \& Komamura (2009) use GAs in the design of energy systems for buildings with a view to designing optimal heating, cooling and power systems. The GA formulation is tested in a case study and produces similar solutions to expert produced designs.

\subsubsection{Neural Networks in Design}

The primary use of neural networks in design is as estimators of key design parameters in domains such as design of steel structures and catalyst design. Several authors also propose their use as assessors of innovative design.

Papadrakakis et al. (2005) note that an important part of designing steel structures should be to ensure reliability and robustness in a way that takes account of the fact that some of the key parameters may be uncertain. To achieve robustness, they utilise neural networks to obtain structures that are least effected by variation in the key parameters whilst at the same time attempting to minimise the weight of a structure. Reddy et al. (2009) develop a feedforward network for estimating the properties of alloys given their composition and heating parameters. The network is able to predict important properties of an alloy such as tensile strength, yield strength and percent elongation, thereby aiding design of alloys.

Several authors utilise neural networks to aid design of catalysts (e.g. (Omata et al. 2005; Song et al. 2007; Tompos et al. 2008; Tompos et al. 2005)). For example, Song et al. (2007) develop a neural network capable of predicting the effect of different forms of $\mathrm{Ni} / \mathrm{Al} 2 \mathrm{O} 3$ 
catalysts on production of hydrogen. The neural network can then be used to design optimal catalysts for producing hydrogen.

There are a number of interesting uses of neural networks for aiding novel design. Lai et al. (2006) suggest the development of neural networks to model user preferences given the form and properties of products. Given such a network, designers can then select the desirable properties of a new product given its form. They illustrate the approach by applying it to model the preferences of mobile phone users and suggest that it is possible to predict the preferred colours of future mobile phones given their physical dimensions. Huang (2008) studies how designers use and revise sketches when aiming to meet user requirements. They then attempt to simulate this behaviour using neural networks thereby hoping that neural networks can be used to identify ambiguous sketches and generate alternative solutions.

\subsubsection{Data Mining in Design}

There are only seven publications on utilising Data Mining methods in Design including the following. Chiu, and Lan (2005) study the potential for using data mining to identify and visualise patterns in collaborative design in construction. Kusiak and Smith (2007) consider the potential uses of data mining in the design of production manufacturing systems with a view to identifying the challenges. Lin and Hong (2008) utilise association rule mining on customer data to identify common behaviour patterns which is then used to aid the design of marketing campaigns and catalogues.

\subsubsection{Hybrid AI in Design}

Surprisingly, the use of hybrid methods has reduced when compared to our previous survey. However, there is a couple of interesting combinations which are worth mentioning.

Identification of failure due to fatigue is a major part of any design, particularly in engineering. Analytical methods alone are not sufficient and experience and experimental methods are also needed. Darlington \& Booker (2006) use a combined CBR and KBS approach to develop an aid for identifying fatigue in designs. They carry out a survey of UK industry to help identify common practice and the main sources of fatigue in designs. From this, they develop a rule base to help designers focus on common causes of fatigue but also develop a case base that facilitates greater coverage of potential types of fatigue.

Fuzzy logic and neural networks are combined by Luo et al. (2007) to develop an aid for designing textile materials by modelling the effect of types of thermal clothing. The authors note that the main advantage of using this combination is that it overcomes the need for a large training set.

\subsection{PROCESS PLANNING AND CONTROL INCLUDING INVENTORY AND SUPPLY CHAIN MANAGEMENT}

The survey has shown a significant increase in the number of published papers in this area. Overall the number of publications has increased from 236 in the 2005 survey to 470 , implying a 4-fold increase in the annual rate of publication since the last survey. Process control remains the most popular area of application having more than $70 \%$ of all 
publications in this area. NNs is the most popular technique followed by GAs, FL and then Data Mining. KBS has sustained a modest level of interest but CBR is catching up with a sixfold increase compared to the 2005 Survey.

\subsubsection{Fuzzy Logic in Process Planning and Control}

The extensive use of FL in process control to manipulate the problem environment is not surprising (Kobbacy et al. 2007). Hence the vast majority of publications involving FL in this area continue to be in process control. Examples include applications in temperature control of continuous stirred tanks(Salehi \& Shahrokhi 2009), control of biodegradation of mixed wastes (Galluzzo \& Cosenza 2009), selection of best silicon crystal slicing technology (Doraid \& Bataineh 2009), application of advanced soft control strategies into the dairy industry(Riverol et al. 2008), controlling spillway gates of dams (Karaboga et al. 2008) and control of steel level of strip casting processes (Park \& Cho 2005).

Examples of using FL in process planning include applications in cost-volume-profit analysis under uncertainty (Yuan 2009) and in change management in construction which involves integrating FL based change prediction model with a system dynamics model of a dynamic planning and control methodology (Motawa et al. 2007).

In Inventory, Lin et al. (2009) propose a new FL controller to enhance search ability of evolutionary algorithms used in logistic network model. Suhail and Khan (2009) study the use of fuzzy control in production inventory systems that contain variable processes with fixed capacity. In supply chain management, a generic qualitative model to assess the degree of collaboration to check feasibility for satisfying the customer requirements using a AHP fuzzy logic model is proposed by Bahinipati et al. (2009). Balan et al. (2009) use FL theory to control the change in errors in forecasted demand between nodes of supply chain and to allow smooth information flow.

\subsubsection{KBS in Process Planning and Control}

KBS is a mature AI technique and as such it maintains researchers' interests albeit at modest overall level. KBSs remain popular in process planning. Examples include applications in metal cutting-punching combination processes (Pan \& Rao 2009) in sheet metal operations (Kumar \& Singh 2008) and in national defence budget planning (Wen et al. 2005). Espasa and Gibert (2005) develop an expert system for the control of emergencies of a process plant.

\subsubsection{CBR in Process Planning and Control}

Although there has been a relatively large increase in interest in CBR, still there are no more than 12 papers on use of CBR in process planning and control. Liu and Yu (2009) used CBR with rough set in a study about smart case-based indexing in worsted roving process. In the construction industry, $\mathrm{Ng}$ and Luu (2008) studied modelling subcontractor registration decision through CBR approach. In process planning, Yang and Wang (2009) have developed a recommender system for software project planning using CBR algorithm, Seo et al. (2007) have developed a process planning system using CBR for block assembly in ship building and Changchien and Lin (2005) have designed a CBR system for marketing plans. In Inventory/ supply chain, Poon et al. (2009) present a resource management CBR system for managing order-picking operations in warehouses and Choy et al. (2009) presents a CBR sample management system for fashion product development. 


\subsubsection{Genetic Algorithms in Process Planning and Control}

There are few applications of GAs in process planning including the study of Salehi and Tavakkoli-Moghaddam (2009) on computer aided process planning in preliminary and detailed planning and implementation and that by To et al. (2009) on the effective use of GAs in coordinating dispersed product development in the fashion industry.

Over the last few years there has been a large increase in using GAs in process control. For example Huang et al. (2009) study the optimum route problem by GA for loading/ unloading of yard cranes, Guo et al. (2009) present a intelligent production control DSS for flexible assembly lines, Perkgoz et al. (2007) use GAs to examine a multi- objective lead time control problem in multistage assembly systems and Chang (2008) studies the use of GAs for guiding rational reservoir flood operations.

In Inventory there has been a considerable increase in interest in using GAs including applications in lot-sizing (Chatfield 2007), two storage inventory model (Roy et al. 2007) and marketing oriented inventory models (Gupta et al. 2007). There has also been increased interest in applying GAs in the closely related area of supply chain management including the work of Borisovsky et al. (2009) on GAs for a supply management, reducing the negative effect of sales promotions using GAs (O'Donnell et al. 2009), hybrid GAs with an adaptive local search scheme for solving multistage-based supply chain problems (Yun et al. 2009), a steady state GA for multi-product supply chain network design (Altiparmak et al. 2009) and a GA for optimal operating parameters of VMI system in a two-echelon supply chain (Nachiappan \& Jawahar 2007).

\subsubsection{Neural Networks in Process Planning and Control}

NNs are the most used AI technique in process planning and control. There has been an increase in the number of publications on use of NNs in process planning and particularly in manufacturing. Examples include applications in precision casting process planning (Vosniakos et al. 2009), automated CAD/CAM integration for die manufacture (Ding \& Matthews 2009), cost estimation for sheet metal parts (Verlinden et al. 2008) and in a synthesis approach to simultaneous process planning and scheduling (Ueda et al. 2007).

Use of NNs in processes control remains one of the most popular applications of AI in operations as they are used to establish process models (Kobbacy et al. 2007). NNs continue to be used as a tool for system identification. We have cited some 150 papers in this category. A useful review article on multiple neural network modelling techniques in process control has been recently published (Ahmed et al. 2009).

There are few studies published on using NNs in supply chain management and the related inventory management area. Examples include service level management of non-stationary supply chain using NN controller (Yoo et al. 2009), application of NNs for supply chain demand forecasting (Carbonneau et al. 2008), modular NNs for recursive collaborative forecasting in the service chain (Stubbings et al. 2008) and comparison of NNs and support vector machines in suppliers' selection (Guosheng \& Guohong 2008). 


\subsubsection{Data Mining in Process Planning and Control}

Data mining use in this area has grown. In process planning Lee et al. (2009) use text mining in patent analysis for technology driven road mapping in business planning, Ayoub et al. (2006) present a planning support system for biomass-based power generation which employs data visualization, data analysis and simulation, Lavrac et al. (2007) use data mining and visualization for decision support and modelling of public health care resources and Jiao and Zhang (2005) develop explicit decision support to improve product portfolio identification by efficient knowledge discovery from past sales and product records.

In process control Xiong et al. (2009) present an adaptive data mining control algorithm in multicarrier networks, Aliev et al. (2008) developed a dynamic data mining technique for rule extraction in a process of battery charging and Xie et al. (2006) propose an approach to predict coiling temperature on run-out table of hot strip mill using data mining.

The few studies found on using data mining in inventory management include the work of Hsu (2009) on use of data mining to improve industrial standards and enhance production and marketing, Chen et al.'s (2005) study on aggregation of orders in distribution centres using data mining and Chen and Wu's (2005) use of association based clustering to order batching based on data mining and integer programming considering customer demand patterns.

Furthermore, there has been a recent increase in the use of data mining in the associated area of supply chain management. Examples include development of a process mining system for supporting knowledge discovery in a supply chain network (Lau et al. 2009b), the use association rule mining for finding key suppliers in a supply chain(R.H. Lin et al. 2009), development of a hybrid mining approach for optimizing returns policies in e-retailing (Yu \& Wang 2008), evaluating supply partner's capability for seasonal products (Hong \& Ha 2008) and mining product maps for new product development(Lia et al. 2008).

\subsubsection{Hybrid AI in Process Planning and Control}

There is a significant increase in number of publications that utilise a hybrid combination of AI techniques. In total there have been 60 papers in this category, with 44 of them in process control. The combinations of two of FL, NN and GA are frequently used and in few papers all three techniques are utilised. Fuzzy Neural Networks are a popular approach with many applications in control. Examples include simulation of a paper mill waste water treatment (Mingzhi et al. 2009), run-to-run controller using numerical simulation analysis for SISO process (C. Wang et al. 2009) and adaptive control on the acoustic field in a duct (K.T. Chen et al. 2008). Another frequently used combination is the use of GAs with FL including the work of Mucientes (2007) on design of a fuzzy controller in mobile robotics using GAs, Poursamad and Montazeri (2008) on design of a genetic fuzzy control strategy for parallel hybrid electric vehicles and van der Lee et al. (2008) on tuning algorithm for model predictive controllers based on GAs and fuzzy decision making. Examples of using NN and GA include applications of a NN for stablization of bipedal standing using a GA (Ghorbani et al. 2007) and predictive control of SOFC based on a GA-RBF NN model (Wu et al. 2008). Applications that use three AI techniques include Cheng et al. (2009) to achieve strategic control over project cash flow. In this work, FL and NN are employed in the EFNIM to develop a neural-fuzzy model that can deal with uncertainties and knowledge mapping and a GA is used to optimize the membership functions of FL and NN parameters globally. 
Another example is the work of Thangavel et al. (2008) on development of a genetic based sensorless hybrid intelligent controller for strip loop formation control between inter-stands in hot steel rolling mills.

There are few applications of hybrid systems in the area of inventory/ supply chain management. Lau et al. (2009a) use a fuzzy logic guided non-dominated sorting GAs to solve a multi-objective vehicle routing optimisation problem. Hanafizadeh et al. (2009) deal with designing a fuzzy-genetic learner model based on multi-agent systems in supply chain management. Examples in inventory management include the work of Sadeghi Moghadam et al. (2008) on lot sizing with supplier selection using a hybrid intelligent algorithm that use GAs, FL, and NNs, and Wu and Hsu (2008) who use a combination of GAs and NNs to design BOM configuration for reducing spare parts logistics costs.

\subsection{SCHEDULING}

Scheduling remains a major area of research with the publication rate growing from around 28 papers per annum in our previous survey to over 40 papers per annum in this survey. The primary growth is due to increasing use of GAs, with 309 publication in the period 20042009 compared to 109 in 1994-2004.

\subsubsection{Fuzzy Logic in Scheduling}

Various researchers have taken advantage of Fuzzy logic's ability to model linguistic variables and uncertainty to aid scheduling. Pan (2005) notes the importance of estimating the effect of rainfall on scheduling construction of roads and develop a fuzzy reasoning system that considers the impact of rainfall on planning construciton of roads. The paper by Bonfatti et al. (2006) argues that most approaches to scheduling falsely assume that parameters, such as quantity and due date, are deterministic and precise. Hence, they develop a model for representing these parameters with fuzzy parameters Petrovic \& Duenas (2006) go further and actually develops a predictive and reactive scheduling system based on fuzzy reasoning. Their system includes a set of fuzzy rules for determining when rescheduling is needed and another set recommends which scheduling heuristics should be utilised for a given situation. The study by Lee (2008) also develops some fuzzy rules for job allocation in a dynamic manner, thereby allowing adaptive job shop scheduling. The results from a trial suggest that this approach produces better results than traditional dispatching heuristics or neural networks.

In the area of project management, Zammori et al. (2009) extend standard critical path methods by adding the ability to specify additional goals on the variability of the duration, and risk of revision which are modelled using fuzzy logic.

\subsubsection{KBS in Scheduling}

There are very few systems that utilise knowledge based systems for scheduling. Yao et al. (2005) develop a system that utilises heuristics capable of scheduling the use of soaking pits for heating material before it is rolled, helping to improve energy utilisation. Hung et al. (2008) develop a novel knowledge based system that aims to aid the design scheduling process taking account of quality and cost. The developed knowledge based system is demonstrated by planning the design of a chip for the semi-conductor industry. 


\subsubsection{CBR in Scheduling}

CBR is reliant on using similar past cases for solving current problems. The nature of scheduling, with varying parameters and the need to optimise tardiness, means that CBR does not necessarily lend itself easily to large scale scheduling problems. Hence the use of CBR for scheduling is minimal. Although simple use of keyword searching indicated seven references in the period 2005-09, most of these had picked up studies on constant bit rate transmission which also utilises the acronym CBR. Apart from studies on constant bit rate in video transmission, there are just two studies that utilises CBR coupled with GAs which we have classified as hybrid use of AI for scheduling (Beddoe \& Petrovic 2006; P.-C. Chang et al. 2006).

\subsubsection{GAs in Scheduling}

The primary use of GAs is for job shop scheduling and project planning.

In job shop scheduling, the main aim is to optimise makespan and tardiness. Different studies have experimented with the use of GAs to tackle this problem under varying conditions, such as single machines vs parallel machines, static vs reactive vs proactive situations and certain vs uncertain information. Some typical studies are summarised below.

Arroyo \& Armentano(2005) develop a GA based search algorithm that aims to preserve some properties of the evolving population to enable optimisation of makespan and tardiness. The developed algorithm is compared to other GA based algorithms and shows good results. Franca et al. (2005) use a similar GA based approach that utilises information about the types of parts to cluster the populations and also consider the use of Memetic algorithms.

Bonfill et al. (2005) utilise stochastic GAs to produce schedules to minimise idle machine time and waiting times in a manner that can handle unexpected events. Several other authors also study how GA based solutions can handle unexpected events ( e.g, (Sakaguchi et al. 2006)).

Chan et al. (2006) argue that job shop scheduling should not only aim to allocate jobs to machines to determine optimal completion times but also take account of maintenance. Hence, they extend the use of GAs that use the dominant gene approach, to take account of additional constraints that represent maintenance schedules. Akturk et al. (2007) formulate the problem of scheduling a Computer Numeric Control (CNC) Machine aimed at minimising completion time and identifying suitable machine operating settings such as cutting time. A key difference between their studies and others is that they model the time for tool change. Balasubramanian et al. (2009) consider the problem of scheduling two distinct types of jobs, each with different criteria to minimise, but on the same type of machines. For one type of job, they are interested in minimising makespan and for the other, the objective is to minimise total duration. They develop both a heuristic method and utilise a bi-criteria genetic algorithm. The results obtained suggest both are comparable in terms of the quality of solutions produced and speed.

Silva et al. (2005) show how a supply chain problem can be cast as a scheduling optimisation problem. They compare three different algorithms: GAs, Ant Colony Optimisation (ACO) and dispatching heuristics and conclude that the GAs and ACO outperform dispatching heuristics, though both ACO and GAs produce similar results. 
Azaron et al. (2005) study the problem of optimising PERT networks where the objective consists of competing terms that represent the completion time and direct cost. Dooley et al. (2005) utilise GAs for optimising transportation of two types of milk from farms in New Zealand that included modelling the varying sizes of farms, the road networks and taking account of the collection costs as well as the revenues. Alba et al. (2007) utilise GAs for planning software projects and consider the impact of various factors on the outcomes.

Barán et al. (2005) evaluate the use of evolutionary algorithms for scheduling pumps aimed at minimising the energy used, keep reservoir levels stable and cost of maintenance.

Several authors study the use of GAs for optimising vehicle routes, aiming to minimise distance and number of vehicles. Alvarenga et al. (2007) apply GAs to the vehicle routing problem with time windows and compare their approach with other heuristics and benchmark data sets and conclude that the results are better than any other published algorithm at the time. Chan \& Chung (2005) use GAs to optimise both transportation and production in a two stage process, first optimising demand and transportation, and then optimising scheduling. This two stage process is applied repeatedly until an acceptable solution is obtained.

Cao et al. (2008) study the problem of scheduling trucks and storage allocation at ports, with the aim of reducing congestion, waiting time and makespan of discharging containers. This study is interesting since the GA doesn't perform as well as a heuristic that they developed, showing GAs may not always provide the best solution.

Apart from job shop scheduling and project scheduling, there are a number of other interesting applications. Kumar et al. (2006) study the use of GAs to schedule adverts on web sites such as Yahoo aimed at maximising revenue based on advert size and frequency. Badia et al. (2009) formulate the problem of routing in wireless mesh networks, where the aim is to optimise delivery of a backlog of data from any one node to another, given availability of the signal to noise ratio between any two potential nodes. The trials suggest the use of GAs has some potential for obtaining good solutions quickly.

\subsubsection{Neural Networks in Scheduling}

The use of neural networks can be broadly categorised in terms of whether feed forward, Hopfield, simulated annealing or self organising maps are used.

Feed forward networks are best at estimation and classification and hence they have normally been used in conjunction with heuristics rather than optimisation methods on their own. So for example, Mönch et al. (2006) develop a dispatching heuristic for scheduling different types of jobs on parallel machines that is based on an estimate of tardiness, requiring parameter estimation. They utilise a neural network and decision tree learning for this parameter estimation and carry out experiments that show this approach works well. Traditionally, several dispatching rules have been developed for scheduling and selection of the most appropriate one for a given circumstance is not obvious, hence Priore et al. (2006) evaluate feed forward neural networks, case based reasoning and inductive learning methods that aim to learn to select the most appropriate dispatching method based on past experience. Fiengo et al. (2007) take a more direct approach and use reinforcement learning to train a 
neural network for scheduling multimedia traffic for mobile phone users based on previous examples. Li et al. (2009) also take a similar approach in training a feed forward network with the aim of allocating bandwidth optimally.

The Hopfield mode has been previously attempted for resource allocation and scheduling. Calabuig et al. (2008) highlights some limitations of the previous attempts, including lack of stability, and provides an alternative formulation that aims to overcome these problems. Dieu \& Ongsakul (2008) use a continuous Hopfield model for hydrothermal scheduling that can take account of constraints on ramp rate limits, fuel, water discharge and water pumps.

A comprehensive review of the use of neural networks for production scheduling can be found in (Akyol \& Bayhan 2007).

\subsubsection{Data Mining in Scheduling}

There are only five attempts at utilising data mining methods for scheduling. These include the work of Kumar and Rao who apply DM methods on schedules generated by Ant Colony Optimisation methods with a view to identifying optimal heuristics that can be utilised by managers carrying out job shop scheduling. Thabtah and Cowling (2008) apply association mining methods to identify heuristics for scheduling personnel and compare the results obtained with the use of decision tree learning methods. Yang et al. (2009) describe the use of decision tree learning methods to predict patient demand for an emergency department of a hospital, thereby aiding scheduling of medical personnel.

\subsubsection{Hybrid AI in Scheduling}

Hybrid approaches aim to bring together the strengths of different technologies. So for example, GAs are known to be useful for optimisation while fuzzy logic is good at representing uncertainty. Examples of studies of this kind include the work of Kim et al. (2005) which combines GAs and fuzzy logic to tackle the problem of scheduling multiple projects and minimise both total duration and tardiness. They compare the hybrid system with a pure GA based approach and conclude that their hybrid system produces better results. Several authors have developed a hybrid approach in which they allow fuzzy parameter for fuzzy demands and constraints that are optimised using an extended GA (P.-T. Chang et al. 2006; Lin 2006).

Chang and Liao (2006) utilise self organising networks coupled with fuzzy logic for predicting the flow time in manufacturing semiconductors. They first use self organising maps on data about the status of the production plant to cluster typical situations and then develop fuzzy rules for those clusters.

One problem with the use of a pure GA based solution to scheduling is that it can require several iterations before finding an acceptable solution. A problem with CBR can occur if a similar case is not available. Chang et al. (2006) suggest a very clever combination of these methods to overcome their weaknesses. Given a scheduling problem, first a CBR system is utilised to retrieve similar cases with their solutions, then these are fed to the initial population of the GA which then hopefully converges quickly to a solution. The solution from the GA is then fed back into the case base for future use. 


\subsection{QUALITY, MAINTENANCE AND FAULT DIAGNOSIS}

Around 200 papers have been published in the review period about applications of AI in quality, maintenance and fault diagnosis. This represents over a two-fold increase in publication rate. Fuzzy logic has the largest increase in publication rate while GAs have the lowest. CBR has doubled the previous publication rate. Data mining has received moderate interest, however in absolute numbers, just under half of all publications in this area use NNs. Applications using hybrid approaches has also increased significantly.

\subsubsection{Fuzzy Logic in Quality, Maintenance and Fault Diagnosis}

Overall, FL application in this area has increased dramatically. There has been marked increase in publications of FL in quality management. In addition to the previously identified area of river water quality (Lermontov et al. 2009), there has been other publications in fuzzy QFD (Quality Function Deployment) approach to achieve quality in modern businesses (Bottani 2009), a FL approach for evaluating agility in supply chains (Jain et al. 2008) and on using fuzzy decision making for evaluation of project management internal efficiency (Dweiri \& Kablan 2006).

Similarly, there has been significant increase in applications of FL in maintenance. Examples of applications include real time decision-making of maintenance using fuzzy agent (Lu \& Sy 2009), opportunistic maintenance based on fuzzy modelling of component proximity (Derigent et al. 2009) and condition evaluation of existing reinforced concrete bridges using fuzzy based (AHP) analytic hierarchy approach (Sasmal \& Ramanjaneyulu 2008).

There are some interesting applications of FL in fault diagnosis. Examples of application areas include fault diagnosis of scooter engines (Wu et al. 2007), pumps (Wang \& Hu 2006), gas turbines (Ogaji et al. 2005a) and DC motors (de Miguel \& Blázquez 2005)

\subsubsection{KBS in Quality, Maintenance and Fault Diagnosis}

KBSs use in this area has increased in the review period. In quality there are very few application areas including software quality improvement (Liu et al. 2006) and classifying lake water chemistry (Saunders et al. 2005). Applications of KBS in maintenance include developing intelligent product manuals (Setchi et al. 2006), the development of an environmental DSS to improve the operation and maintenance of constructed wetlands (Turon et al. 2007) and a KBS for maintenance planning of highway concrete bridges (Chassiakos et al. 2005). In fault diagnosis, KBSs are used in implementation of knowledge maintenance modules in an expert system for fault diagnosis of chemical process plants (Qian et al. 2005), fault diagnosis of a chemical process operation, real time fault diagnosis of a lubricating oil refining process (Qian et al. 2008), a Web-based hydro turbine fault diagnosis system (Song et al. 2008) and in motorcycle maintenance (Su et al. 2006).

\subsubsection{CBR in Quality, Maintenance and Fault Diagnosis}

There are only few uses of CBR in quality, maintenance and fault diagnosis. In quality management we found an application aimed at managing congestion in $3 \mathrm{G}$ networks (Chantaraskul \& Cuthbert 2008). In maintenance, Chou (2009) study early cost budgeting for pavement maintenance and Cheng et al. (2008) present a framework for intelligent reliability centred maintenance analysis. In fault diagnosis, Liu and Cheraghi (2006) use 
CBR with a generic intelligent system in design to address the non-conformance tracking and diagnosis problem.

\subsubsection{GAs in Quality, Maintenance and Fault Diagnosis}

There are very few examples of applications of GAs in quality management including a model for prediction of highway runoff quality (Opher \& Friedler 2009), and a study on water quality management in a reservoir/river system(Kerachian \& Karamouz 2007). There are more applications in maintenance including designing a risk-informed balanced system using a genetic algorithm (Podofillini \& Zio 2008), studies on optimising outage maintenance schedule (Hadavi 2008), selecting optimal repair and rehabilitation methods for reinforced concrete bridge decks (Lee \& Kim 2007), multi-year preventive maintenance program (Chootinan et al. 2006) and a model for preventive maintenance planning (Lapa et al. 2006). There has also been interest in application of GAs in fault diagnosis including power transformer (Fei \& Zhang 2009), water hydraulic motor (Chen et al. 2006) and gas turbine(Ogaji et al. 2005b).

\subsubsection{Neural Networks in Quality, Maintenance and Fault Diagnosis}

Application of NNs in quality has become popular with 16 papers published in the review period. Examples include monitoring high-yield processes with defects count in nonconforming items (Abbasi \& Akhavan Niaki 2007), using recurrent neural networks to detect changes in auto correlated process for quality monitoring (Pacella \& Semeraro 2007) and in quality control by ultrasonic testing in resistance spot welding (Martín et al. 2007). Other applications are in the areas of forecasting water quality in distribution systems (May et al.), importance-performance analysis model (Hu et al. 2009) and modelling service quality from the view point of management (Lin 2007). We found no papers in the maintenance area but fault diagnosis remains a very popular area of application of NNs. There are very many examples including fault diagnosis of pneumatic systems (Demetgul et al. 2009), automotive generators (Wu \& Kuo 2009), engines (Wu \& Liu 2008), solar thermal applications (Kalogirou et al. 2008) and a suck rod pumping system (Xu et al. 2007).

\subsubsection{Data Mining in Quality, Maintenance and Fault Diagnosis}

In quality management we found some applications of data mining such as use of data mining to improve personnel selection (Chien \& Chen 2008), in estimating the impact of project management policies on software quality (Moreno García et al. 2008) and to enable customer relationship in ISP services through mining usage patterns(Li et al. 2006).

We found no publications on using data mining in maintenance. In fault diagnosis there are few publications including the work of Hou et al. (2006) on yield enhancement in semiconductor manufacturing and Zhang et al. (2005) who used data mining to extract features in fault diagnosis of machines.

\subsubsection{Hybrid AI in Quality, Maintenance and Fault Diagnosis}


Interest in hybrid applications in this area has increased significantly. In quality management there are papers on fuzzy CBR on quality management in GPRS networks(Pulkkinen et al. 2008), a fuzzy DEA-neural approach to measuring design services performance in PCM projects (C.-H. Wang et al. 2009) and a neural-genetic algorithm for reservoir water quality management (Kuo et al. 2006). In maintenance Christodoulou et al. (2009) develop a neurofuzzy approach for risk-based assessment management of water piping networks and Celeux et al. (2006) design a Bayesian network for preventive maintenance from expert opinion. In fault diagnosis neuro-fuzzy techniques are used frequently e.g. by Zio and Gola(2009) for rotating machinery and Chen et al. (2008) for railway track circuits. Nan et al. (2008) present a knowledge based expert system for process industry using FL to make inferences based on the acquired information and knowledge. Rafiee et al.(2009) presents an optimised gear fault identification system using GAs and NNs. Yu et al.(2008) develop a hybrid learning-based model for on-line intelligent monitoring and diagnosis of manufacturing processes using a knowledge base, NNs and GAs. Hou et al.(2006) introduce a strategy based on data mining for detection and diagnosis of faults in heating, ventilating and air conditioning systems using a combined rough set approach and $\mathrm{NN}$.

\section{CONCLUSIONS}

This paper has surveyed the use of AI in operations management with a view to identifying trends, gaps and directions for future research. The survey uses the same methodology, the same categories of operations management and AI methods considered in our previous work in order to facilitate comparison and identification of trends over a longer time period. An additional AI methods, that of data mining, is added to this study to recognise its growing use in many applications.

What are the major uses of AI in operations management? Table 1 summarise the data from this survey and Figure 1 shows the number of publications utilising AI methods in each area of operations management based on a combination of the data from this survey and our previous work . As Figure 1 shows, there has been substantial use of GAs in scheduling, with many studies recognising their flexibility and potential for optimising objectives. There has also been significant research on the use of GAs in design that takes advantage of their capabilities to evolve alternative designs; use of neural networks for estimation of key parameters that guide designs; and use of the capabilities of case-based reasoning to reuse past designs.

Figure 1 shows the increasing and more dominant use of neural networks in Quality, Maintenance and Fault Diagnosis and Process Planning and Control. The applications of NNs in Process Control count for more than $70 \%$ of all publications in the area of Process Planning and Control. GAs remain among the major techniques used in Process Planning and Control for the reasons mentioned above. The steady growth in the use of fuzzy logic in Process Planning and Control reflects the increasing need to model uncertainty for this area of operations management. 


\begin{tabular}{|l|c|c|c|c|c|c|r||r|}
\hline & $\begin{array}{l}\text { Fuzzy } \\
\text { Logic }\end{array}$ & KBS & CBR & GAs & NN & $\begin{array}{l}\text { Data } \\
\text { Mining }\end{array}$ & Hybrid & Total \\
\hline Design & 40 & 2 & 33 & 210 & 86 & 7 & 16 & 394 \\
\hline Scheduling & 14 & 2 & 0 & 309 & 38 & 5 & 21 & 389 \\
\hline $\begin{array}{l}\text { Process Planning } \\
\text { and Control }\end{array}$ & 77 & 8 & 12 & 104 & 173 & 36 & 60 & 470 \\
\hline $\begin{array}{l}\text { Quality \& } \\
\text { Maintenance } \\
\text { and Fault Diagnosis }\end{array}$ & 27 & 17 & 6 & 25 & 89 & 11 & 31 & 206 \\
\hline Total & 158 & 29 & 51 & 648 & 386 & 59 & 128 & 1459 \\
\hline
\end{tabular}

Table 1: Number of publications from 2005 to 2009.

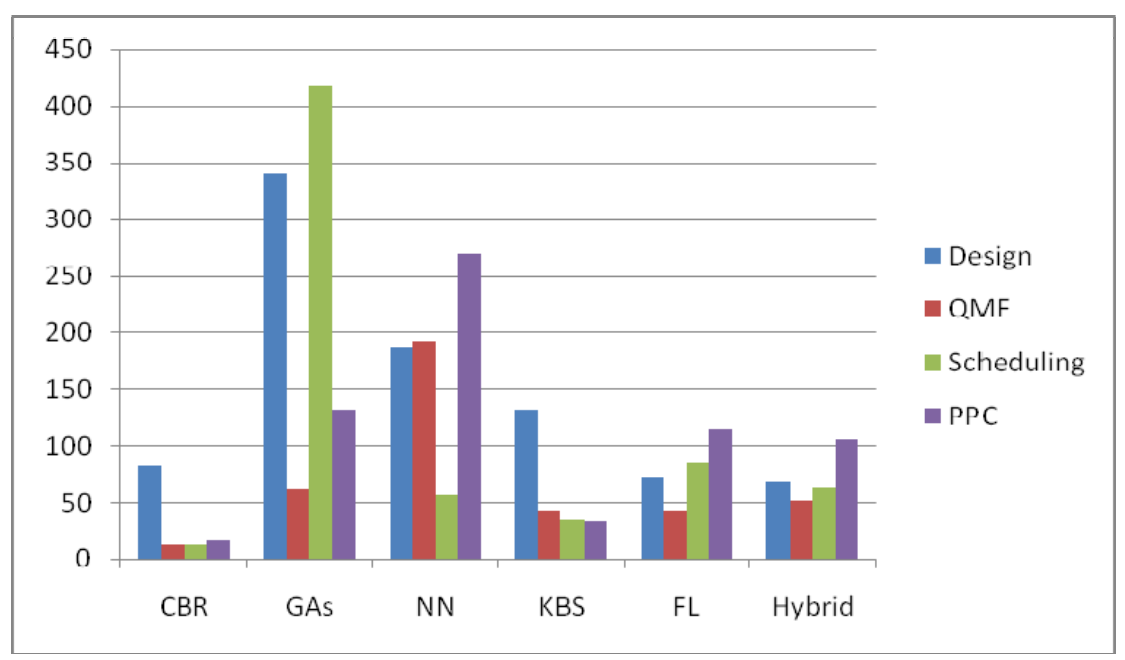

Figure 1: No of publications of AI in Operations Management from 1995-2009

What are the trends in use of AI in operations management? Figure 2, below, presents the trends, extending our previous work with the data from this study. The trends for Design and Scheduling show a dramatic increase in the use of GAs since 2003-04 that reflect recognition of their success in these areas. There is a steady stream of 20 to 35 publications bi-annually that utilise neural networks for design over the last decade. The decline in use of KBS in design from over 40 publications in 1995-96 to just the odd paper in recent times is also evident. This trend, visible across all areas of operations management, is not too surprising since KBS have been well studied since the 1980s, are now well understood and no longer considered novel technology. The use of fuzzy logic, CBR, hybrid methods and data mining has been relatively low and typically around 10 publications bi-annually.

In the area of Process Planning and Control papers using GAs have shown the largest increase in rate of publication compared with the previous survey around 7 fold increase. That is followed by the six fold increase of the rate of publication using CBR which reflects the need to represent and utilise past experience. FL applications also show significant 
increase while KBS has declined further in use, representing less than $2 \%$ of publications in this area.

In the area of Quality, Maintenance and Fault Diagnosis, the biggest rate increase was in the use of FL followed by moderate increase in publications using CBR and NNs. Publications in both KBS and GAs in this area remained at their previous modest levels with 5 or less papers each year.

Despite their relatively limited use to date, the number of papers using Hybrid Systems has increased significantly, by 3 fold, in both areas of Quality, Maintenance and Fault Diagnosis and Process Planning and Control. ${ }^{1}$
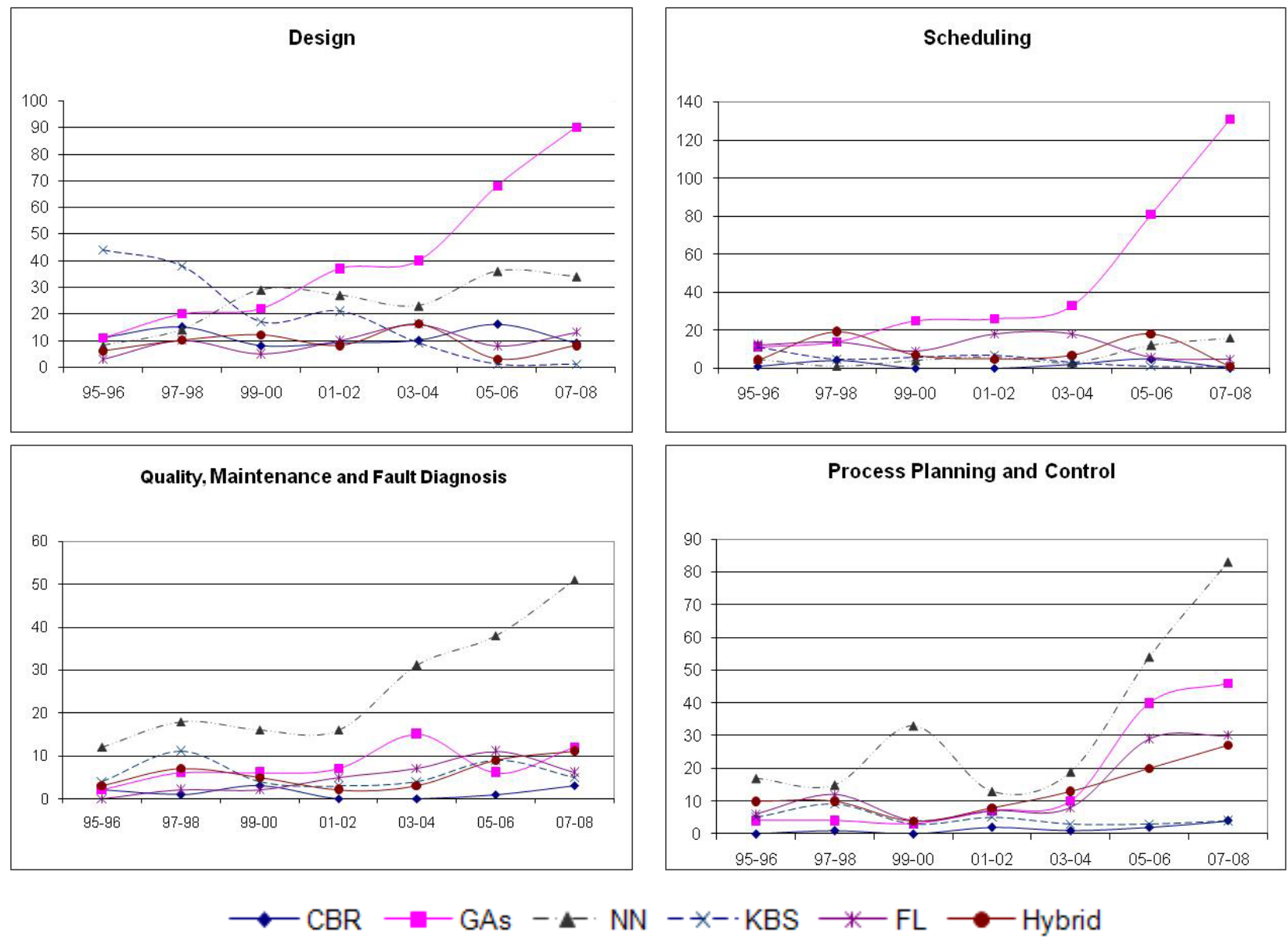

Figure 2: Bi-annual trends from 1995 to 2008

What are the gaps and future directions? The increasing uses of GAs and NNs, shown in Figure 1, can be expected to continue to grow in the future. Given their ability to find patterns, the use data mining in Operations management can also be expected to grow significantly and is already starting to become evident in the area of Process Planning and Control. The relative lack of a significant number of publications in the use of CBR and hybrid methods in operations management represents an opportunity for further research. Creating new designs, assessing quality, fault diagnosis, scheduling and maintenance are all

\footnotetext{
${ }^{1}$ Figures 1 and 2 are based in part on data/figures that appeared in the paper by Kobbacy, Vadera, Rasmy (2007) published in the Journal of the Operational Research Society
} 
areas where past experience must play a significant role and one can therefore expect significant gains by using CBRs capability to represent past experience. The limited use of hybrid methods in Design and Scheduling thus far offers a fruitful direction of research in which the different strengths of the AI methods could combine to produce improvements over current results.

In conclusion, this paper has identified some notable trends, gaps and directions for future research in the use of AI methods in operations management. 


\section{REFERENCES}

Ababneh, M, Almanasreh, AM \& Amasha, H 2009, 'Design of digital controllers for uncertain chaotic systems using fuzzy logic', Journal of the Franklin Institute, vol. 346, no. 6, pp. 543-556.

Abbasi, B \& Akhavan Niaki, ST 2007, 'Monitoring high-yields processes with defects count in nonconforming items by artificial neural network', Applied Mathematics and Computation, vol. 188, no. 1, pp. 262270.

Ahmed, Z, Noor, RAM \& Zhang, J 2009, 'Multiple neural networks modelling techniques in process control: a review', Asian Pacific Journal of Chemical Engineering, vol. 4, no. 4, pp. 403-417.

Akturk, MS, Ghosh, JB \& Kayan, RK 2007, 'Scheduling with tool changes to minimize total completion time under controllable machining conditions', Computers \& Operations Research, vol. 34, no. 7, pp. 21302146.

Akyol, DE \& Bayhan, GM 2007, 'A review on evolution of production scheduling with neural networks', Computers \& Industrial Engineering, vol. 53, no. 1, pp. 95-122.

Alba, E \& Francisco Chicano, J 2007, 'Software project management with GAs', Information Sciences, vol. 177, no. 11, pp. 2380-2401.

Aliev, RA, Aliev, RR, Guirimov, B \& Uyar, K 2008, 'Dynamic data mining technique for rules extraction in a process of battery charging', Applied Soft Computing, vol. 8, no. 3, pp. 1252-1258.

Altiparmak, F, Gen, M, Lin, L \& Karaoglan, I 2009, 'A steady-state genetic algorithm for multi-product supply chain network design', Computers \& Industrial Engineering, vol. 56, no. 2, pp. 521-537.

Alvarenga, GB, Mateus, GR \& de Tomi, G 2007, 'A genetic and set partitioning two-phase approach for the vehicle routing problem with time windows', Computers \& Operations Research, vol. 34, no. 6, pp. 1561-1584.

Andújar, JM \& Barragán, AJ 2005, 'A methodology to design stable nonlinear fuzzy control systems', Fuzzy Sets and Systems, vol. 154, no. 2, pp. 157-181.

Arroyo, JEC \& Armentano, VA 2005, 'Genetic local search for multi-objective flowshop scheduling problems', European Journal of Operational Research, vol. 167, no. 3, pp. 717-738.

Avramenko, Y \& Kraslawski, A 2005, 'Decision supporting system for pre-selection of column internals in reactive distillation', Chemical Engineering and Processing, vol. 44, no. 6, pp. 609-616.

Avramenko, Y \& Kraslawski, A 2006, 'Similarity concept for case-based design in process engineering', Computers \& Chemical Engineering, vol. 30, no. 3, pp. 548-557.

Ayoub, N, Wang, K, Kagiyama, T, Seki, H \& Naka, Y 2006, 'A planning support system for biomass-based power generation', Computer Aided Chenical Engineering, vol. 21, no. 2, pp. 1899-1904.

Azaron, A, Perkgoz, C \& Sakawa, M 2005, 'A genetic algorithm approach for the time-cost trade-off in PERT networks', Applied Mathematics and Computation, vol. 168, no. 2, pp. 1317-1339.

Badia, L, Botta, A \& Lenzini, L 2009, 'A genetic approach to joint routing and link scheduling for wireless mesh networks', Ad Hoc Networks, vol. 7, no. 4, pp. 654-664.

Bahinipati B K , Kanda A \& G, DS 2009, 'Horizontal collaboration in semiconductor manufacturing industry supply chain: An evaluation of collaboration intensity index', Computers \& Industrial Engineering, vol. 57, no. 3, pp. 880-895.

Balan, S, Vrat, P \& Kumar, P 2009, 'Information distortion in a supply chain and its mitigation using soft computing approach', Omega, vol. 37, no. 2, pp. 282-299.

Balasubramanian, H, Fowler, J, Keha, A \& Pfund, M 2009, 'Scheduling interfering job sets on parallel machines', European Journal of Operational Research, vol. 199, no. 1, pp. 55-67.

Barán, B, von Lücken, C \& Sotelo, A 2005, 'Multi-objective pump scheduling optimisation using evolutionary strategies', Advances in Engineering Software, vol. 36, no. 1, pp. 39-47.

Beddoe, GR \& Petrovic, S 2006, 'Selecting and weighting features using a genetic algorithm in a case-based reasoning approach to personnel rostering', European Journal of Operational Research, vol. 175, no. 2, pp. 649-671.

Bonfatti, M, Caridi, M \& Schiavina, L 2006, 'A fuzzy model for load-oriented manufacturing control', International Journal of Production Economics, vol. 104, no. 2, pp. 502-513.

Bonfill, A, Espuña, A, Puigjaner, L, Luis, P \& Antonio, E 2005, 'Proactive approach to address robust batch process scheduling under short-term uncertainties', in Computer Aided Chemical Engineering, vol. Volume 20, Part 2, Elsevier, pp. 1057-1062.

Borisovsky, P, Dolgui, A \& Eremeev, A 2009, 'Genetic algorithms for a supply management problem: MIPrecombination vs greedy decoder', European Journal of Operational Research, vol. 195, no. 3, pp. 770-779.

Bottani, E 2009, 'A fuzzy QFD approach to achieve agility', International Journal of Production Economics, vol. 119 , no. 2 , pp. 380-391. 
Calabuig, D, Monserrat, JF, Gómez-Barquero, D \& Lázaro, O 2008, 'An efficient dynamic resource allocation algorithm for packet-switched communication networks based on Hopfield neural excitation method', Neurocomputing, vol. 71, no. 16-18, pp. 3439-3446.

Cao, J, Shi, Q \& Lee, D-H 2008, 'A Decision Support Method for Truck Scheduling and Storage Allocation Problem at Container', Tsinghua Science \& Technology, vol. 13, no. Supplement 1, pp. 211-216.

Carbonneau, R, Laframboise, K \& Vahidov, R 2008, 'Application of machine learning techniques for supply chain demand forecasting', European Journal of Operational Research, vol. 184, no. 3, pp. 1140-1154.

Celeux, G, Corset, F, Lannoy, A \& Ricard, B 2006, 'Designing a Bayesian network for preventive maintenance from expert opinions in a rapid and reliable way', Reliability Engineering \& System Safety, vol. 91, no. 7, pp. 849-856.

Chan, FTS \& Chung, SH 2005, 'Multicriterion genetic optimization for due date assigned distribution network problems', Decision Support Systems, vol. 39, no. 4, pp. 661-675.

Chan, FTS, Chung, SH, Chan, LY, Finke, G \& Tiwari, MK 2006, 'Solving distributed FMS scheduling problems subject to maintenance: Genetic algorithms approach', Robotics and Computer-Integrated Manufacturing, vol. 22, no. 5-6, pp. 493-504.

Chang, L-C 2008, 'Guiding rational reservoir flood operation using penalty-type genetic algorithm', Journal of Hydrology, vol. 354, no. 1-4, pp. 65-74.

Chang, P-C, Hsieh, J-C \& Liu, C-H 2006, 'A case-injected genetic algorithm for single machine scheduling problems with release time', International Journal of Production Economics, vol. 103, no. 2, pp. 551564.

Chang, P-T, Yao, M-J, Huang, S-F \& Chen, C-T 2006, 'A genetic algorithm for solving a fuzzy economic lotsize scheduling problem', International Journal of Production Economics, vol. 102, no. 2, pp. 265-288.

Chang, PC \& Liao, TW 2006, 'Combining SOM and fuzzy rule base for flow time prediction in semiconductor manufacturing factory', Applied Soft Computing, vol. 6, no. 2, pp. 198-206.

Changchien, SW \& Lin, M-C 2005, 'Design and implementation of a case-based reasoning system for marketing plans', Expert Systems with Applications, vol. 28, no. 1, pp. 43-53.

Chantaraskul, S \& Cuthbert, L 2008, 'An intelligent-agent approach for congestion management in 3G networks', Engineering Applications of Artificial Intelligence, vol. 21, no. 4, pp. 619-632.

Chassiakos, AP, Vagiotas, P \& Theodorakopoulos, DD 2005, 'A knowledge-based system for maintenance planning of highway concrete bridges', Advances in Engineering Software, vol. 36, no. 11-12, pp. 740749.

Chatfield, DC 2007, 'The economic lot scheduling problem: A pure genetic search approach', Computers \& Operations Research, vol. 34, no. 10, pp. 2865-2881.

Che, J \& Tang, S 2008, 'Research on integrated optimization design of hypersonic cruise vehicle', Aerospace Science and Technology, vol. 12, no. 7, pp. 567-572.

Chen, HX, Chua, PSK \& Lim, GH 2006, 'Adaptive wavelet transform for vibration signal modelling and application in fault diagnosis of water hydraulic motor', Mechanical Systems and Signal Processing, vol. 20, no. 8, pp. 2022-2045.

Chen, J, Roberts, C \& Weston, P 2008, 'Fault detection and diagnosis for railway track circuits using neurofuzzy systems', Control Engineering Practice, vol. 16, no. 5, pp. 585-596.

Chen, KT, Chou, CH, Chang, SH \& Liu, YH 2008, 'Adaptive fuzzy neural network control on the acoustic field in a duct', Applied Acoustics, vol. 69, no. 6, pp. 558-565.

Chen, M-C, Huang, C-L, Chen, K-Y \& Wu, H-P 2005, 'Aggregation of orders in distribution centers using data mining', Expert Systems with Applications, vol. 28, no. 3, pp. 453-460.

Chen, M-C \& Wu, H-P 2005, 'An association-based clustering approach to order batching considering customer demand patterns', Omega, vol. 33, no. 4, pp. 333-343.

Cheng, M-Y, Tsai, H-C \& Liu, C-L 2009, 'Artificial intelligence approaches to achieve strategic control over project cash flows', Automation in Construction, vol. 18, no. 4, pp. 386-393.

Cheng, Z, Jia, X, Gao, P, Wu, S \& Wang, J 2008, 'A framework for intelligent reliability centered maintenance analysis', Reliability Engineering \& System Safety, vol. 93, no. 6, pp. 806-814.

Chien, C-F \& Chen, L-F 2008, 'Data mining to improve personnel selection and enhance human capital: A case study in high-technology industry', Expert Systems with Applications, vol. 34, no. 1, pp. 280-290.

Chiu, M-L \& Lan, J-H 2005, 'Information and IN-formation: Information mining for supporting collaborative design', Automation in Construction, vol. 14, no. 2, pp. 197-205.

Chootinan, P, Chen, A, Horrocks, MR \& Bolling, D 2006, 'A multi-year pavement maintenance program using a stochastic simulation-based genetic algorithm approach', Transportation Research Part A: Policy and Practice, vol. 40, no. 9, pp. 725-743.

Chou, J-S 2009, 'Web-based CBR system applied to early cost budgeting for pavement maintenance project', Expert Systems with Applications, vol. 36, no. 2, Part 2, pp. 2947-2960. 
Choy, KL, Chow, KH, Moon, KL, Zeng, X, Lau, HCW, Chan, FTS \& Ho, GTS 2009, 'A RFID-case-based sample management system for fashion product development', Engineering Applications of Artificial Intelligence, vol. 22, no. 6, pp. 882-896.

Christodoulou, S, Deligianni, A, Aslani, P \& Agathokleous, A 2009, 'Risk-based asset management of water piping networks using neurofuzzy systems', Computers, Environment and Urban Systems, vol. 33, no. 2, pp. 138-149.

Cortes Robles, G, Negny, S \& Le Lann, JM 2008, 'Design acceleration in chemical engineering', Chemical Engineering and Processing: Process Intensification, vol. 47, no. 11, pp. 2019-2028.

Cortes Robles, G, Negny, S \& Le Lann, JM 2009, Case-based reasoning and TRIZ: A coupling for innovative conception in Chemical Engineering, vol. 48, pp. 239-249.

Darlington, JF \& Booker, JD 2006, 'Development of a design technique for the identification of fatigue initiating features', Engineering Failure Analysis, vol. 13, no. 7, pp. 1134-1152.

Davies, J, Goel, AK \& Nersessian, NJ 2009, 'A computational model of visual analogies in design', Cognitive Systems Research, vol. 10, no. 3, pp. 204-215.

de Miguel, LJ \& Blázquez, LF 2005, 'Fuzzy logic-based decision-making for fault diagnosis in a DC motor', Engineering Applications of Artificial Intelligence, vol. 18, no. 4, pp. 423-450.

Degertekin, SO, Saka, MP \& Hayalioglu, MS 2008, 'Optimal load and resistance factor design of geometrically nonlinear steel space frames via tabu search and genetic algorithm', Engineering Structures, vol. 30, no. 1, pp. 197-205.

Demetgul, M, Tansel, IN \& Taskin, S 2009, 'Fault diagnosis of pneumatic systems with artificial neural network algorithms', Expert Systems with Applications, vol. 36, no. 7, pp. 10512-10519.

Derigent, W, Thomas, E, Levrat, E \& Iung, B 2009, 'Opportunistic maintenance based on fuzzy modelling of component proximity', CIRP Annals - Manufacturing Technology, vol. 58, no. 1, pp. 29-32.

Dieu, VN \& Ongsakul, W 2008, 'Enhanced merit order and augmented Lagrange Hopfield network for hydrothermal scheduling', International Journal of Electrical Power \& Energy Systems, vol. 30, no. 2, pp. 93-101.

Ding, L \& Matthews, J 2009, 'A contemporary study into the application of neural network techniques employed to automate CAD/CAM integration for die manufacture', Computers \& Industrial Engineering, vol. 57, no. 4, pp. 1457-1471.

Dooley, AE, Parker, WJ \& Blair, HT 2005, 'Modelling of transport costs and logistics for on-farm milk segregation in New Zealand dairying', Computers and Electronics in Agriculture, vol. 48, no. 2, pp. 7591.

Doraid, D \& Bataineh, O 2009, 'A fuzzy logic approach to the selection of the best silicon crystal slicing technology', Expert Systems with Applications, vol. 36, no. 2, pp. 3712-3719.

Dweiri, FT \& Kablan, MM 2006, 'Using fuzzy decision making for the evaluation of the project management internal efficiency', Decision Support Systems, vol. 42, no. 2, pp. 712-726.

Espasa, ML, Gibert, FB, Luis, P \& Antonio, E 2005, 'Expert system for the control of emergencies of a process plant', in Computer Aided Chemical Engineering, vol. Volume 20, Part 2, Elsevier, pp. 1489-1493.

Farinha, F, Portela, E, Domingues, C \& Sousa, L 2005, 'Knowledge-based systems in civil engineering: Three case studies', Advances in Engineering Software, vol. 36, no. 11-12, pp. 729-739.

Fei, S-w \& Zhang, X-b 2009, 'Fault diagnosis of power transformer based on support vector machine with genetic algorithm', Expert Systems with Applications, vol. 36, no. 8, pp. 11352-11357.

Fiengo, P, Giambene, G \& Trentin, E 2007, 'Neural-based downlink scheduling algorithm for broadband wireless networks', Computer Communications, vol. 30, no. 2, pp. 207-218.

França, PM, Gupta, JND, Mendes, AS, Moscato, P \& Veltink, KJ 2005, 'Evolutionary algorithms for scheduling a flowshop manufacturing cell with sequence dependent family setups', Computers \& Industrial Engineering, vol. 48, no. 3, pp. 491-506.

Galluzzo, M \& Cosenza, B 2009, 'Control of the biodegradation of mixed wastes in a continuous bioreactor by a type-2 fuzzy logic controller', Computers \& Chemical Engineering, vol. 33, no. 9, pp. 1475-1483.

Ghorbani, R, Wu, Q \& Wang, GG 2007, 'Nearly optimal neural network stabilization of bipedal standing using genetic algorithm', Engineering Applications of Artificial Intelligence, vol. 20, no. 4, pp. 473-480.

Guo Z X, Wong W K, Leung S Y S \& T., FJ 2009, 'Intelligent production control decision support system for flexible assembly lines', Expert Systems with Applications vol. 36, no. 3, pp. 4268-4277.

Guosheng, H \& Guohong, Z 2008, 'Comparison of neural networks and support vector machines in suppliers' selection', Journal of Systems Engineering and Electronics, vol. 19, no. 2, pp. 316-320.

Gupta, RK, Bhunia, AK \& Goyal, SK 2007, 'An application of genetic algorithm in a marketing oriented inventory model with interval valued inventory costs and three-component demand rate dependent on displayed stock level', Applied Mathematics and Computation, vol. 192, no. 2, pp. 466-478.

Hadavi, SMH 2008, 'Risk-Based, genetic algorithm approach to optimize outage maintenance schedule', Annals of Nuclear Energy, vol. 35, no. 4, pp. 601-609. 
Hanafizadeh, P \& Sherkat, MH 2009, 'Designing fuzzy-genetic learner model based on multi-agent systems in supply chain management', Expert Systems with Applications, vol. 36, no. 6, pp. 10120-10134.

Hernández, C \& Arjona, MA 2007, 'Design of distribution transformers based on a knowledge-based system and 2D finite elements', Finite Elements in Analysis and Design, vol. 43, no. 8, pp. 659-665.

Hong, G \& Ha, SH 2008, 'Evaluating partner's capability for seasonal produxts using machine learning techniques', Computers \& Industrial Engineering, vol. 54, no. 4, pp. 721-736.

Hou, Z, Lian, Z, Yao, Y \& Yuan, X 2006, 'Data mining based sensor fault diagnosis and validation for building air conditioning system', Energy Conversion and Management, vol. 47, no. 15-16, pp. 2479-2490.

Hsu, C-H 2009, 'Data mining to improve industrial standards and enhance production and marketing: An empirical study in apparel industry', Expert Systems with Applications, vol. 36, no. 3, Part 1, pp. 41854191.

Hu, H-Y, Lee, Y-C, Yen, T-M \& Tsai, C-H 2009, 'Using BPNN and DEMATEL to modify importanceperformance analysis model - A study of the computer industry', Expert Systems with Applications, vol. 36, no. 6, pp. 9969-9979.

Huang, Y 2008, 'Investigating the cognitive behavior of generating idea sketches through neural network systems', Design Studies, vol. 29, no. 1, pp. 70-92.

Huang Y, Liang C \& Y, Y 2009, 'The optimum route problem by genetic algorithm for loading/ unloading of yard crane', Computers \& Industrial Engineering, vol. 56, no. 3, pp. 993-1001.

Hung, H-F, Kao, H-P \& Juang, Y-S 2008, 'An integrated information system for product design planning', Expert Systems with Applications, vol. 35, no. 1-2, pp. 338-349.

Jain, V, Benyoucef, L \& Deshmukh, SG 2008, 'A new approach for evaluating agility in supply chains using Fuzzy Association Rules Mining', Engineering Applications of Artificial Intelligence, vol. 21, no. 3, pp. 367-385.

Jiao, J \& Zhang, YF 2005, 'Product portfolio identification based on association rule mining', Computer Aided Design, vol. 37, no. 2, pp. 149-172.

Kalogirou, S, Lalot, S, Florides, G \& Desmet, B 2008, 'Development of a neural network-based fault diagnostic system for solar thermal applications', Solar Energy, vol. 82, no. 2, pp. 164-172.

Karaboga, D, Bagis, A \& Haktanir, T 2008, 'Controlling spillway gates of dams by using fuzzy logic controller with optimum rule number', Applied Soft Computing, vol. 8, no. 1, pp. 232-238.

Kaveh, A \& Rahami, H 2006, 'Nonlinear analysis and optimal design of structures via force method and genetic algorithm', Computers \& Structures, vol. 84, no. 12, pp. 770-778.

Kerachian, R \& Karamouz, M 2007, 'A stochastic conflict resolution model for water quality management in reservoir-river systems', Advances in Water Resources, vol. 30, no. 4, pp. 866-882.

Kim, K, Yun, Y, Yoon, J, Gen, M \& Yamazaki, G 2005, 'Hybrid genetic algorithm with adaptive abilities for resource-constrained multiple project scheduling', Computers in Industry, vol. 56, no. 2, pp. 143-160.

Kobbacy, KA, Vadera, S \& Rasmi, M 2007, 'AI and OR in management of operations: history and trends', Journal of the Operational Research Society, vol. 58, pp. 10-28.

Kumar, S, Jacob, VS \& Sriskandarajah, C 2006, 'Scheduling advertisements on a web page to maximize revenue', European Journal of Operational Research, vol. 173, no. 3, pp. 1067-1089.

Kumar, S \& Rao, CSP, 'Application of ant colony, genetic algorithm and data mining-based techniques for scheduling', Robotics and Computer-Integrated Manufacturing, vol. In Press, Corrected Proof.

Kumar, S \& Singh, R 2008, 'Automation of strip-layout design for sheet metal work on progressive die', Journal of Materials Processing Technology, vol. 195, no. 1-3, pp. 94-100.

Kuo, J-T, Wang, Y-Y \& Lung, W-S 2006, 'A hybrid neural-genetic algorithm for reservoir water quality management', Water Research, vol. 40, no. 7, pp. 1367-1376.

Kuo, T-C, Wu, H-H \& Shieh, J-I 2009, 'Integration of environmental considerations in quality function deployment by using fuzzy logic', Expert Systems with Applications, vol. 36, no. 3, Part 2, pp. 71487156.

Kusiak, A \& Smith, M 2007, 'Data mining in design of products and production systems', Annual Reviews in Control, vol. 31, no. 1, pp. 147-156.

Lai, H-H, Lin, Y-C, Yeh, C-H \& Wei, C-H 2006, 'User-oriented design for the optimal combination on product design', International Journal of Production Economics, vol. 100, no. 2, pp. 253-267.

Lai, I-C \& Chang, T-W 2006, 'A distributed linking system for supporting idea association during the conceptual design stage', Design Studies, vol. 27, no. 6, pp. 685-710.

Lapa, CMF, Pereira, CMNA \& de Barros, MP 2006, 'A model for preventive maintenance planning by genetic algorithms based in cost and reliability', Reliability Engineering \& System Safety, vol. 91, no. 2, pp. 233-240.

Lau, HCW, Chan, TM, Tsui, WT, Chan, FTS, Ho, GTS \& Choy, KL 2009a, 'A fuzzy guided multi-objective evolutionary algorithm model for solving transportation problem', Expert Systems with Applications, vol. 36 , no. 4 , pp. $8255-8268$. 
Lau, HCW, Ho, GTS, Zhao, Y \& Chung, NSH 2009b, 'Development of a process mining system for supporting knowledge discovery in a supply chain network', International Journal of Production Economics, vol. 122, no. 1, pp. 176-187.

Lavrac, N, Bohanec, M, Pur, A, Cestnik, B, Debeljak, M \& Kobler, A 2007, 'Data mining and visualization for decision support and modeling of public health-care resources', Journal of Biomedical Informatics, vol. 40, no. 4, pp. 438-447.

Lee, C-K \& Kim, S-K 2007, 'GA-based algorithm for selecting optimal repair and rehabilitation methods for reinforced concrete (RC) bridge decks', Automation in Construction, vol. 16, no. 2, pp. 153-164.

Lee, JH 2007, 'Optimization of indoor climate conditioning with passive and active methods using GA and CFD', Building and Environment, vol. 42, no. 9, pp. 3333-3340.

Lee, KK 2008, 'Fuzzy rule generation for adaptive scheduling in a dynamic manufacturing environment', Applied Soft Computing, vol. 8, no. 4, pp. 1295-1304.

Lee, S, Yoon, B, Lee, C \& Park, J 2009, 'Business planning based on technological capabilities: Patent analysis for technology-driven roadmapping', Technological Forecasting and Social Change, vol. 76, no. 6, pp. 769-786.

Lermontov, A, Yokoyama, L, Lermontov, M \& Machado, MAS 2009, 'River quality analysis using fuzzy water quality index: Ribeira do Iguape river watershed, Brazil', Ecological Indicators, vol. 9, no. 6, pp. 11881197.

Li, S-T, Shue, L-Y \& Lee, S-F 2006, 'Enabling customer relationship management in ISP services through mining usage patterns', Expert Systems with Applications vol. 30, no. 4, pp. 621-636.

Li, Z-X, Wang, W-L \& Cheng, X-M 2009, 'Optimal Bandwidth Scheduling for Resource-constrained Networks', Acta Automatica Sinica, vol. 35, no. 4, pp. 443-448.

Lia, SH, Hsieh, CL \& Huang, SP 2008, 'Mining product maps for new product development', Expert Systems with Applications, vol. 34, no. 1, pp. 50-62.

Lin, C-M 2006, 'Multiobjective fuzzy competence set expansion problem by multistage decision-based hybrid genetic algorithms', Applied Mathematics and Computation, vol. 181, no. 2, pp. 1402-1416.

Lin, C \& Hong, C 2008, 'Using customer knowledge in designing electronic catalog', Expert Systems with Applications, vol. 34, no. 1, pp. 119-127.

Lin, L, Gen, M \& Wang, X 2009, 'Integrated multistage logistics network design by using hybrid evolutionary algorithm', Computers \& Industrial Engineering, vol. 56, no. 3, pp. 854-873.

Lin, RH, Chuang, CL, Lion, JJH \& Wu, GD 2009, 'An integrated method for finding key suppliers in SCM', Expert Systems with Applications, vol. 36, no. 3, pp. 6461-6465.

Lin, W-B 2007, 'An empirical of service quality model from the viewpoint of management', Expert Systems with Applications, vol. 32, no. 2, pp. 364-375.

Liu, G \& Yu, W 2009, 'Smart case-based indexing in worsted roving process: Combination of rough set and case-based reasoning', Applied Mathematics and Computation, vol. 214, no. 1, pp. 280-286.

Liu, W \& Cheraghi, SH 2006, 'Design and implementation of a generic nonconformance tracking and recovery (GINTR) system', Computers in Industry, vol. 57, no. 7, pp. 631-639.

Liu, XF, Kane, G \& Bambroo, M 2006, 'An intelligent early warning system for software quality improvement and project management', Journal of Systems and Software, vol. 79, no. 11, pp. 1552-1564.

Lu, K-Y \& Sy, C-C 2009, 'A real-time decision-making of maintenance using fuzzy agent', Expert Systems with Applications, vol. 36, no. 2, Part 2, pp. 2691-2698.

Luo, X, Hou, W, Li, Y \& Wang, Z 2007, 'A fuzzy neural network model for predicting clothing thermal comfort', Computers \& Mathematics with Applications, vol. 53, no. 12, pp. 1840-1846.

Martín, Ó, López, M \& Martín, F 2007, 'Artificial neural networks for quality control by ultrasonic testing in resistance spot welding', Journal of Materials Processing Technology, vol. 183, no. 2-3, pp. 226-233.

May, RJ, Dandy, GC, Maier, HR \& Nixon, JB, 'Application of partial mutual information variable selection to ANN forecasting of water quality in water distribution systems', Environmental Modelling \& Software, vol. 23, no. 10-11, pp. 1289-1299.

Mingzhi, H, Ma, Y, Jinquan, W \& W., Y 2009, 'Simulation of a paper mill wastewater treatment using fuzzy neural network', Expert Systems with Applications, vol. 36, no. 3, pp. 5064-5070.

Mönch, L, Zimmermann, J \& Otto, P 2006, 'Machine learning techniques for scheduling jobs with incompatible families and unequal ready times on parallel batch machines', Engineering Applications of Artificial Intelligence, vol. 19, no. 3, pp. 235-245.

Moreno García, MN, Román, IR, García Peñalvo, FJ \& Bonilla, MT 2008, 'An association rule mining method for estimating the impact of project management policies on software quality, development time and effort', Expert Systems with Applications, vol. 34, no. 1, pp. 522-529.

Motawa, IA, Anumba, CJ, Lee, S \& Peña-Mora, F 2007, 'An integrated system for change management in construction', Automation in Construction, vol. 16, no. 3, pp. 368-377. 
Mucientes, M, Moreno, DL, Bugarín, A \& Barro, S 2007, 'Design of a fuzzy controller in mobile robotics using genetic algorithms', Applied Soft Computing, vol. 7, no. 2, pp. 540-546.

Nachiappan, SP \& Jawahar, N 2007, 'A genetic algorithm for optimal operating parameters of VMI system in a two-echelon supply chain', European Journal of Operational Research, vol. 182, no. 3, pp. 1433-1452.

Nan, C, Khan, F \& Iqbal, MT 2008, 'Real-time fault diagnosis using knowledge-based expert system', Process Safety and Environmental Protection, vol. 86, no. 1, pp. 55-71.

Narayana Naik, G, Gopalakrishnan, S \& Ganguli, R 2008, 'Design optimization of composites using genetic algorithms and failure mechanism based failure criterion', Composite Structures, vol. 83, no. 4, pp. 354-367.

Ng, S-tT \& Luu, CDT 2008, 'Modeling subcontractor registration decisions through case-based reasoning approach', Automation in Construction, vol. 17, no. 7, pp. 873-881.

O'Donnell, T, Humphreys, P, McIvor, R \& Maguire, L 2009, 'Reducing the negative effects of sales promotions in supply chains using genetic algorithms', Expert Systems with Applications, vol. 36, no. 4, pp. 78277837.

Ogaji, SOT, Marinai, L, Sampath, S, Singh, R \& Prober, SD 2005a, 'Gas-turbine fault diagnostics: a fuzzy-logic approach', Applied Energy, vol. 82, no. 1, pp. 81-89.

Ogaji, SOT, Sampath, S, Marinai, L, Singh, R \& Probert, SD 2005b, 'Evolution strategy for gas-turbine faultdiagnoses', Applied Energy, vol. 81, no. 2, pp. 222-230.

Omata, K, Kobayashi, Y \& Yamada, M 2005, 'Artificial neural network-aided development of supported Co catalyst for preferential oxidation of CO in excess hydrogen', Catalysis Communications, vol. 6, no. 8, pp. 563-567.

Ooka, R \& Komamura, K 2009, 'Optimal design method for building energy systems using genetic algorithms', Building and Environment, vol. 44, no. 7, pp. 1538-1544.

Opher, T \& Friedler, E 2009, 'A preliminary coupled MT-GA model for the prediction of highway runoff quality', Science of The Total Environment, vol. 407, no. 15, pp. 4490-4496.

Pacella, M \& Semeraro, Q 2007, 'Using recurrent neural networks to detect changes in autocorrelated processes for quality monitoring', Computers \& Industrial Engineering, vol. 52, no. 4, pp. 502-520.

Pan, M \& Rao, Y 2009, 'An integrated knowledge based system for sheet metal cutting-punching combination processing', Knowledge-Based Systems, vol. 22, no. 5, pp. 368-375.

Pan, N-F 2005, 'Assessment of productivity and duration of highway construction activities subject to impact of rain', Expert Systems with Applications, vol. 28, no. 2, pp. 313-326.

Papadrakakis, M, Lagaros, ND \& Plevris, V 2005, 'Design optimization of steel structures considering uncertainties', Engineering Structures, vol. 27, no. 9, pp. 1408-1418.

Park, Y \& Cho, H 2005, 'A fuzzy logic controller for the molten steel level control of strip casting processes', Control Engineering Practice, vol. 13, no. 7, pp. 821-834.

Perkgoz C, Azaron A, Katagiri H, Kato K \& M., S 2007, 'A multi-objective lead time control problem in multistage assembly using fenetic algorithms', European Journal of Operational Research, vol. 180, no. 1, pp. 292-308.

Petrovic, D \& Duenas, A 2006, 'A fuzzy logic based production scheduling/rescheduling in the presence of uncertain disruptions', Fuzzy Sets and Systems, vol. 157, no. 16, pp. 2273-2285.

Podofillini, L \& Zio, E 2008, 'Designing a risk-informed balanced system by genetic algorithms: Comparison of different balancing criteria', Reliability Engineering \& System Safety, vol. 93, no. 12, pp. 1842-1852.

Poon, TC, Choy, KL, Chow, HKH, Lau, HCW, Chan, FTS \& Ho, KC 2009, 'A RFID case-based logistics resource management system for managing order-picking operations in warehouses', Expert Systems with Applications, vol. 36, no. 4, pp. 8277-8301.

Poursamad, A \& Montazeri, M 2008, 'Design of genetic-fuzzy control strategy for parallel hybrid electric vehicles', Control Engineering Practice, vol. 16, no. 7, pp. 861-873.

Priore, P, de la Fuente, D, Puente, J \& Parreño, J 2006, 'A comparison of machine-learning algorithms for dynamic scheduling of flexible manufacturing systems', Engineering Applications of Artificial Intelligence, vol. 19, no. 3, pp. 247-255.

Pulkkinen, P, Laurikkala, M, Ropponen, A \& Koivisto, H 2008, 'Quality management in GPRS networks with fuzzy case-based reasoning', Knowledge-Based Systems, vol. 21, no. 5, pp. 421-428.

Qian, Y, Xu, L, Li, X, Lin, L \& Kraslawski, A 2008, 'LUBRES: An expert system development and implementation for real-time fault diagnosis of a lubricating oil refining process', Expert Systems with Applications, vol. 35, no. 3, pp. 1252-1266.

Qian, Y, Zheng, M, Li, X \& Lin, L 2005, 'Implementation of knowledge maintenance modules in an expert system for fault diagnosis of chemical process operation', Expert Systems with Applications, vol. 28, no. 2, pp. 249-257. 
Rafiee, J, Tse, PW, Harifi, A \& Sadeghi, MH 2009, 'A novel technique for selecting mother wavelet function using an intelligent fault diagnosis system', Expert Systems with Applications, vol. 36, no. 3, Part 1, pp. $4862-4875$.

Reddy, NS, Krishnaiah, J, Hong, S-G \& Lee, JS 2009, 'Modeling medium carbon steels by using artificial neural networks', Materials Science and Engineering: A, vol. 508, no. 1-2, pp. 93-105.

Riverol, C, Ricart, G, Carosi, C \& Di Santis, C 2008, 'Application of advanced soft control strategies into the dairy industry', Innovative Food Science \& Emerging Technologies, vol. 9, no. 3, pp. 298-305.

Roy, A, Maiti, MK, Kar S. \& Maiti, M 2007, 'Two storage inventory model with fuzzy deterioration over a random planning horizon', Mathematical and Computer Modelling, vol. 46, no. 11-12, pp. 1419-1433.

Sadeghi Moghadam, MR, Afsar, A \& Sohrabi, B 2008, 'Inventory lot-sizing with supplier selection using hybrid intelligent algorithm', Applied Soft Computing, vol. 8, no. 4, pp. 1523-1529.

Sakaguchi, T, Tanimizu, Y, Harada, K, Iwamura, K, Sugimura, N, Eiji, A \& Tatsuo, A 2006, 'Genetic algorithm based reactive scheduling in manufacturing system - advanced crossover method for tardiness minimization problems', in Mechatronics for Safety, Security and Dependability in a New Era, Elsevier, Oxford, pp. 207-212.

Salehi, M \& Tavakkoli-Moghaddam, R 2009, 'Application of genetic algorithm to computer-aided process planning in preliminary and detailed planning', Engineering Applications of Artificial Intelligence, vol. 22, no. 8, pp. 1179-1187.

Salehi, S \& Shahrokhi, M 2009, 'Adaptive fuzzy backstepping approach for temperature control of continuous stirred tank reactors', Fuzzy Sets and Systems, vol. 160, no. 12, pp. 1804-1818.

Sasmal, S \& Ramanjaneyulu, K 2008, 'Condition evaluation of existing reinforced concrete bridges using fuzzy based analytic hierarchy approach', Expert Systems with Applications, vol. 35, no. 3, pp. 1430-1443.

Saunders, MC, Sullivan, TJ, Nash, BL, Tonnessen, KA \& Miller, BJ 2005, 'A knowledge-based approach for classifying lake water chemistry', Knowledge-Based Systems, vol. 18, no. 1, pp. 47-54.

Seo, Y, Sheen, D \& Kim, T 2007, 'Block assembly planning in shipbuilding using case-based reasoning', Expert Systems with Applications, vol. 32, no. 1, pp. 245-253.

Setchi, RM, Pham, DT \& Dimov, SS 2006, 'A methodology for developing intelligent product manuals', Engineering Applications of Artificial Intelligence, vol. 19, no. 6, pp. 657-669.

Silva, CA, Sousa, JMC, Runkler, T \& Palm, R 2005, 'Soft computing optimization methods applied to logistic processes', International Journal of Approximate Reasoning, vol. 40, no. 3, pp. 280-301.

Song, G, He, Y, Chu, F \& Gu, Y 2008, 'HYDES: A Web-based hydro turbine fault diagnosis system', Expert Systems with Applications, vol. 34, no. 1, pp. 764-772.

Song, S, Akande, AJ, Idem, RO \& Mahinpey, N 2007, 'Inter-relationship between preparation methods, nickel loading, characteristics and performance in the reforming of crude ethanol over Ni/Al2O3 catalysts: A neural network approach', Engineering Applications of Artificial Intelligence, vol. 20, no. 2, pp. 261271.

Stubbings, P, Virninas, B, Owusu, G \& Voudouris, C 2008, 'Modular neural networks for recursive collaborative forecasting in the service chain', Knowledge-based systems, vol. 21, no. 6, pp. 450-457.

Su, K-W, Hwang, S-L \& Chou, Y-F 2006, 'Applying knowledge structure to the usable fault diagnosis assistance system: A case study of motorcycle maintenance in Taiwan', Expert Systems with Applications, vol. 31, no. 2, pp. 370-382.

Suhail, A \& Khan, ZA 2009, 'Fuzzy production control with limited resources and response delay', Computers \& Industrial Engineering, vol. 56, no. 1, pp. 433-443.

Thabtah, F \& Cowling, P 2008, 'Mining the data from a hyperheuristic approach using associative classification', Expert Systems with Applications, vol. 34, no. 2, pp. 1093-1101.

Thangavel, S, Palanisamy, V \& Duraiswamy, K 2008, 'Genetic based sensorless hybrid intelligent controller for strip loop formation control between inter-stands in hot steel rolling mills', ISA Transactions, vol. 47, no. 2, pp. 179-188.

To, CKM, Fung, H-K, Harwood, RJ \& Ho, KC 2009, 'Coordinating dispersed product development processes: A contingency perspective of project design and modelling', International Journal of Production Economics, vol. 120, pp. 570-584.

Tompos, A, Hegedus, M, Margitfalvi, JL, Szabó, EG \& Végvári, L 2008, 'Multicomponent Au/MgO catalysts designed for selective oxidation of carbon monoxide: Application of a combinatorial approach', Applied Catalysis A: General, vol. 334, no. 1-2, pp. 348-356.

Tompos, A, Margitfalvi, JL, Tfirst, E, Végvári, L, Jaloull, MA, Khalfalla, HA \& Elgarni, MM 2005, 'Development of catalyst libraries for total oxidation of methane: A case study for combined application of "holographic research strategy and artificial neural networks" in catalyst library design', Applied Catalysis A: General, vol. 285, no. 1-2, pp. 65-78. 
Turon, C, Comas, J, Alemany, J, Cortés, U \& Poch, M 2007, 'Environmental decision support systems: A new approach to support the operation and maintenance of horizontal subsurface flow constructed wetlands', Ecological Engineering, vol. 30, no. 4, pp. 362-372.

Ueda, K, Fujii, N \& Inoue, R 2007, 'An emergent synthesis approach to simultaneous process planning and scheduling', CIRP Annals-Manufacturing Technology vol. 56, no. 1, pp. 463-466.

Vakili-Ardebili, A \& Boussabaine, AH 2007, 'Application of fuzzy techniques to develop an assessment framework for building design eco-drivers', Building and Environment, vol. 42, no. 11, pp. 3785-3800.

van der Lee, JH, Svrcek, WY \& Young, BR 2008, 'A tuning algorithm for model predictive controllers based on genetic algorithms and fuzzy decision making', ISA Transactions, vol. 47, no. 1, pp. 53-59.

Verlinden, B, Duflou, JR, Collin, P \& Cattrysse, D 2008, 'Cost estimation for sheet metal parts using multiple regression and artificial neural networks: A case study', International Journal of Production Economics, vol. 111, no. 2, pp. 484-492.

Vosniakos, GC, Galiotou, V, Pantelis, D, Benardos, P \& Pavlou, P 2009, 'The scope of artificial neural network metamodels for precision casting process planning', Robotics and Computer-Integrated Manufacturing, vol. 25, no. 6, pp. 909-916.

Wang, C-H, Chuang, C-C \& Tsai, C-C 2009, 'A fuzzy DEA-Neural approach to measuring design service performance in PCM projects', Automation in Construction, vol. 18, no. 5, pp. 702-713.

Wang, C, Jiang, B, Wu, MY \& Jen, CH 2009, 'Evaluation of fuzzy neural network run-to-run controller using numerical simulation analysis for SISO process', Expert Systems with Applications, vol. 36, no. 10, pp. 12044-12048.

Wang, J \& Hu, H 2006, 'Vibration-based fault diagnosis of pump using fuzzy technique', Measurement, vol. 39, no. 2, pp. 176-185.

Wang, W, Rivard, H \& Zmeureanu, R 2006, 'Floor shape optimization for green building design', Advanced Engineering Informatics, vol. 20, no. 4, pp. 363-378.

Wen, W, Wang, WK \& Wang, CH 2005, 'A knowledge-based intelligent decision support system for national defense budget planning', Expert Systems with Applications, vol. 28, no. 1, pp. 55-66.

Wu, J-D \& Kuo, J-M 2009, 'An automotive generator fault diagnosis system using discrete wavelet transform and artificial neural network', Expert Systems with Applications, vol. 36, no. 6, pp. 9776-9783.

$\mathrm{Wu}, \mathrm{J}-\mathrm{D} \& \mathrm{Liu}, \mathrm{C}-\mathrm{H} 2008$, 'Investigation of engine fault diagnosis using discrete wavelet transform and neural network', Expert Systems with Applications, vol. 35, no. 3, pp. 1200-1213.

Wu, J-D, Wang, Y-H \& Bai, MR 2007, 'Development of an expert system for fault diagnosis in scooter engine platform using fuzzy-logic inference', Expert Systems with Applications, vol. 33, no. 4, pp. 1063-1075.

Wu, M-C \& Hsu, Y-K 2008, 'Design of BOM configuration for reducing spare parts logistic costs', Expert Systems with Applications, vol. 34, no. 4, pp. 2417-2423.

Wu, X-J, Zhu, X-J, Cao, G-Y \& Tu, H-Y 2008, 'Predictive control of SOFC based on a GA-RBF neural network model', Journal of Power Sources, vol. 179, no. 1, pp. 232-239.

Xie, HB, Jiang, ZY, Liu, XH, Wang, GD \& Tieu, AK 2006, 'Prediction of coiling temperature on run-out table of hot strip mill using data mining', Journal of Materials Processing Technology, vol. 177, no. 1-3, pp. 121-125.

Xiong, N, Yang, LT \& Li, Y 2009, 'ODMCA: An adaptive data mining control algorithm in multicarrier networks', Computer Communications, vol. 32, no. 3, pp. 560-567.

$\mathrm{Xu}, \mathrm{P}, \mathrm{Xu}, \mathrm{S} \& \mathrm{Yin}, \mathrm{H} 2007$, 'Application of self-organizing competitive neural network in fault diagnosis of suck rod pumping system', Journal of Petroleum Science and Engineering, vol. 58, no. 1-2, pp. 43-48.

Yang, CC, Lin, WT, Chen, HM \& Shi, YH 2009, 'Improving scheduling of emergency physicians using data mining analysis', Expert Systems with Applications, vol. 36, no. 2, Part 2, pp. 3378-3387.

Yang, H-L \& Wang, C-S 2009, 'Recommender system for software project planning one application of revised CBR algorithm', Expert Systems with Applications, vol. 36, no. 5, pp. 8938-8945.

Yao, L, Postlethwaite, I, Browne, W, Gu, D, Mar, M \& Lowes, S 2005, 'Design, implementation and testing of an intelligent knowledge-based system for the supervisory control of a hot rolling mill', Journal of Process Control, vol. 15, no. 6, pp. 615-628.

Yoo, JS, Hong, SR \& Kim, CO 2009, 'Service level management of nonstationary supply chain using direct neural network controller', Expert Systems with Applications, vol. 36, no. 2, Part 2, pp. 3574-3586.

Yu, C-C \& Wang, C-S 2008, 'A hybrid mining approach for optimizing returns policies in e-retailing', Expert Systems with Applications, vol. 35, no. 4, pp. 1575-1582.

$\mathrm{Yu}, \mathrm{J}, \mathrm{Xi}, \mathrm{L} \&$ Zhou, X 2008, 'Intelligent monitoring and diagnosis of manufacturing processes using an integrated approach of KBANN and GA', Computers in Industry, vol. 59, no. 5, pp. 489-501.

Yuan, F-C 2009, 'The use of a fuzzy logic-based system in cost-volume-profit analysis under uncertainty', Expert Systems with Applications, vol. 36, no. 2, Part 1, pp. 1155-1163. 
Yun, Y, Moon, C \& Kim, D 2009, 'Hybrid genetic algorithm with adaptive local search scheme for solving multistage-based supply chain problems', Computers \& Industrial Engineering, vol. 56, no. 3, pp. 821838.

Zammori, FA, Braglia, M \& Frosolini, M 2009, 'A fuzzy multi-criteria approach for critical path definition', International Journal of Project Management, vol. 27, no. 3, pp. 278-291.

Zhang, S, Mathew, J, Ma, L \& Sun, Y 2005, 'Best basis-based intelligent machine fault diagnosis', Mechanical Systems and Signal Processing, vol. 19, no. 2, pp. 357-370.

Zio, E \& Gola, G 2009, 'A neuro-fuzzy technique for fault diagnosis and its application to rotating machinery', Reliability Engineering \& System Safety, vol. 94, no. 1, pp. 78-88. 